\title{
Comparison of Different Liquid Crystal Materials under Planar and Homeotropic Boundary Conditions in Capillaries
}

\author{
M.S. Chychlowski ${ }^{a}$, S. Ertman ${ }^{a}$, E. Nowinowski-Kruszelnicki ${ }^{b}$, R. DAzBrowski $^{b}$ \\ AND T.R. WOLIŃSKI ${ }^{a, *}$ \\ ${ }^{a}$ Faculty of Physics, Warsaw University of Technology, Koszykowa 75, 00-662 Warszawa, Poland \\ ${ }^{b}$ Military University of Technology, Gen. S. Kaliskiego 2, 00-908 Warszawa, Poland
}

\begin{abstract}
We present a thermally-induced liquid crystal orientation method by applying an extra orienting layer onto an inner capillary surface that can induce either planar or homeotropic liquid crystal boundary conditions. Experimental evidence of boundary-induced orientation in two types of liquid crystal (nematic, chiral nematic) in a capillary are shown.
\end{abstract}

PACS: 42.70.Df, 61.30.Jf, 77.84.Nh, 42.79.Kr

\section{Introduction}

Photonic crystal fibers (PCFs) are a new type of optical fibers with their physical properties significantly improved [1-3]. PCFs infiltrated with liquid crystals (LCs) create photonic liquid crystal fibers (PLCFs), that can be used as dynamically tuned photonic devices or sensors for various quantities [4-11]. Principle of operation of PLCF devices is based on change in propagation light properties induced by a change in LC molecules orientation.

LC molecules [12] rearrangement depends on various factors such as boundary conditions, elastic deformation constants of the LC, physical geometry of the container and quality of the aligning layer. PLCF-based sensors or controllers are devices that utilize a PCF (photonic crystal with 2D lattice of air tubes with diameter of few micrometers) filled with a LC. For these reasons a special technique should be applied to control LC molecule alignment within the PCF air holes. Quality of LC orientation plays a predominant role in propagation of light within the PLCF. There are several ways for achieving specific LC molecular orientation in LC cells but majority of them cannot be straightforwardly applied to PCFs [13-18]. To indirect methods used for LC orienting belong thermally-induced layer. The thermally-activated polymer layer creates and enforces LC orientation, and the method itself is based on a chemical process which under high temperature creates an orienting structure [19]. The advantage of the polymers, from applications point of view, is that their properties cannot be changed during typical work of photonic device and there is no direct influence of the light propagating inside the fiber with orienting layer.

To analyze orientation inside a PLCF we used a capillary - a single element of the periodic photonic crystal fiber structure. Capillaries have one of the most spe-

* corresponding author; e-mail: wolinski@if.pw.edu.pl cific boundary conditions due to their cylindrical shape. As homeotropic and planar orienting materials we used SE-1211 and SE-130 (Nissan Chemical Industries, Ltd) polymers, respectively [19]. Two types of LC mixtures were used: nematic LC (NLC) and chiral nematic LC CNLC) (manufactured at the Military University of Technology - MUT, Warsaw, Poland) [20, 21]. Capillaries which we used were of diameter of few micrometers (8-13) (manufactured at the Maria Curie-Skłodowska University - UMCS, Lublin, Poland).

An experimental setup and the sample preparation procedure have been reported elsewhere [22, 23]. The main process of orienting layer deposition is to append a monomer onto inner surface of a capillary and heat it up to polymerize polymide. The sample under the measurement is placed between crossed or parallel polarizers in microscope at some angle in polarizers plane.

\section{Results}

6CHBT NLC (composed of rod-like shaped molecules) was introduced into capillaries with two induced boundary conditions and then compared with samples without additional layers (no anchoring conditions) as a reference. Figure 1 presents micrographs taken under polarizing microscope of $13 \mu \mathrm{m}$ capillary filled with the NLC. Orientation achieved by this procedure is generally planar.

In Fig. 2, there are micrographs of the sample taken under polarizing microscope of $13 \mu \mathrm{m}$ capillary with an additional LC homogenic alignment induced by a layer of the SE-130 polimide and filled with 6CHBT. This layer enforced planar LC molecules alignment especially at the inner surface of the capillary.

The micrographs presented in Fig. 3, taken under the polarizing microscope, show a $13 \mu \mathrm{m}$ capillary with an additional LC homeotropic alignment induced by a layer of the SE-1211 polimide and filled with 6CHBT. This layer induces perpendicular alignment of the LC molecules to the inner surface of the capillary. Due to 


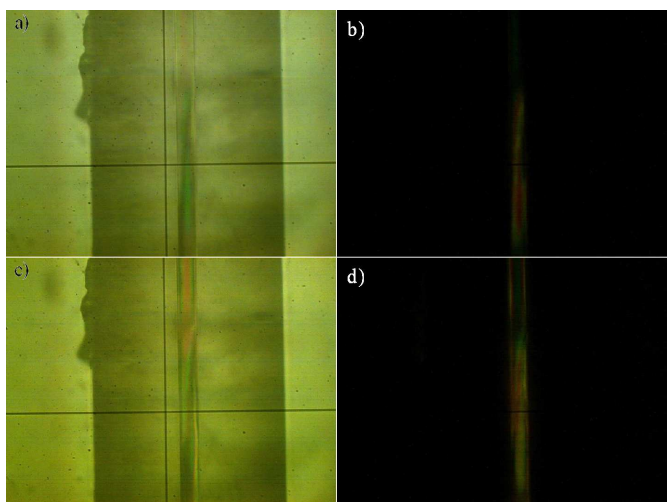

Fig. 1. Sample of NLC without any alignment material on inner surface of the capillary micrographs under polarizing microscope with (a) parallel polarizers and capillary long axis parallel to polarization axis, (b) crossed polarizers and capillary long axis parallel to one of the polarization axis, (c) parallel polarizers and capillary long axis at $45^{\circ}$ to polarization axis, (d) crossed polarizers and capillary long axis at $45^{\circ}$ to polarization axis.

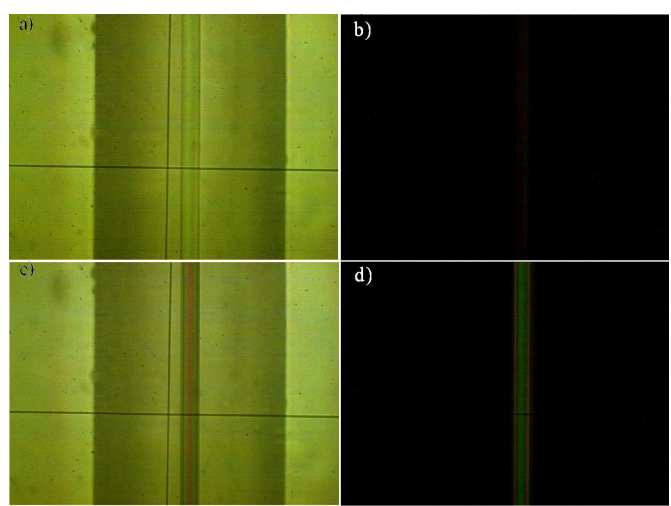

Fig. 2. Sample of NLC with planar alignment material on inner surface of the capillary micrographs under polarizing microscope. Parts (a)-(d) as in Fig. 1.

minimization of free energy, LC molecular layers bend themselves into the direction of the long capillary axis. The section of the capillary filled with LC can be divided into darker and brighter regions. These regions correspond to LC molecules orientation causing change of the linearly polarized light.

Another type of LC was PW700 CNLC, with the $0.4 \mu \mathrm{m}$ helical pitch. It presents a different orientation due to twist between quasi-nematic LC layers. Similarly to previous study, three samples of CNLC were prepared and measured in the same configuration as the NLC. Figure 4 shows sample without any aligning layer. There is no simple orientation of LC inside a capillary. Figure $4 \mathrm{~d}$ presents a continuous and not periodic change in the transmitted light along the sample axis. This continuous change is caused by a chiral nature of the CNLC and no boundary conditions result in a random planar

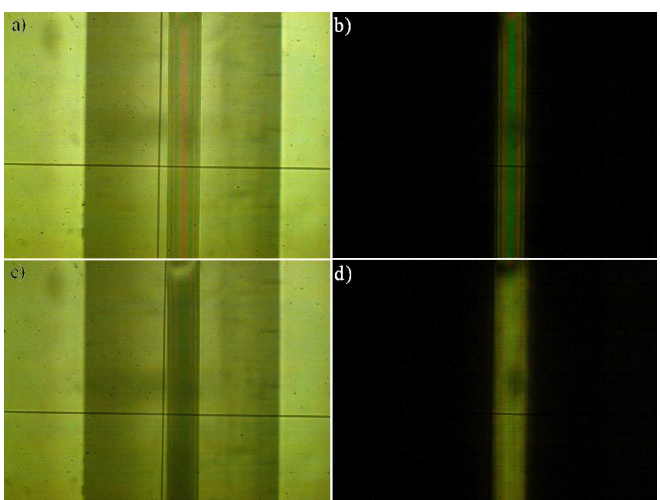

Fig. 3. Sample of NLC with homeotropic alignment material on inner surface of the capillary micrographs under polarizing microscope. Parts (a)-(d) as in Fig. 1.

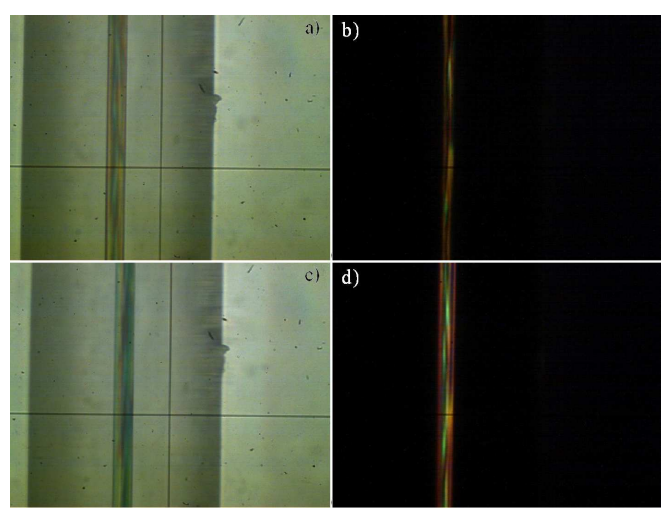

Fig. 4. Sample of CNLC without any alignment material on inner surface of the capillary micrographs under polarizing microscope. Parts (a)-(d) as in Fig. 1.

alignment of the molecules at the inner surface of the capillary.

The samples with prepared planar aligning layer (Fig. 5) have stable continuous orientation with negligible fluctuation seen in Fig. 5d. The polarized light transmittance indicates that CNLC molecule layers twist but the helicoidal pitch is perpendicular to the capillary long axis and is different than for a LC cell.

The homeotropic boundary conditions applied to a sample with the PW700 CNLC resulted in the most stable and continuous orientation (Fig. 6). Molecules were aligned perpendicularly to the inner surface of the capillary and the LC director is bending to main capillary axis with the decreasing radius. This orientation resembles splay/escaped radial orientation of the NLC. Notice that the periodic nature of the CNLC was not observed.

\section{Conclusion}

We have demonstrated the thermally-activated aligning technique applied to different LC phases. The combination of the same boundary conditions for NLC and 


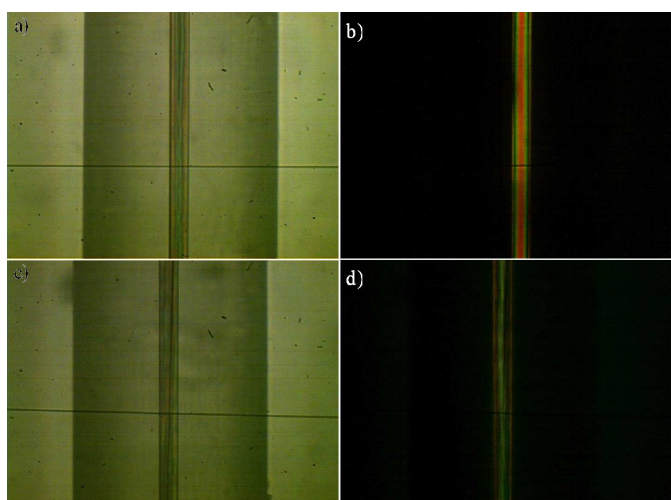

Fig. 5. Sample of CNLC with planar alignment material on inner surface of the capillary micrographs under polarizing microscope. Parts (a)-(d) as in Fig. 1.

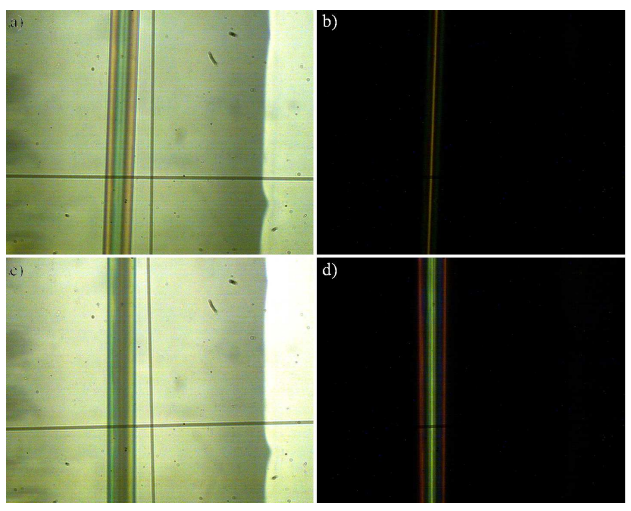

Fig. 6. Sample of CNLC with homeotropic alignment material on inner surface of the capillary micrographs under polarizing microscope. Parts (a)-(d) as in Fig. 1.

CNLC can result in two distinct orientations. The thermally-induced alignment increases repeatability and uniform LC molecular orientation along the capillary long axis.

\section{Acknowledgments}

This work was supported by the Polish Ministry of Science and Education under the grants N N517 554139 and N N507 439539 and partially by the MISTRZ Programme of the Polish Science Foundation. M. Chychłowski acknowledges the European Social Fund through the Warsaw University of Technology Development Programme granted by the European Union.

\section{References}

[1] J.C. Knight, Nature 424, 847 (2003).

[2] R. Buczynski, Acta Phys. Pol. A 106, 141 (2004).
[3] P.St.J. Russell, J. Lightwave Technol. (2006).

[4] T.R. Woliński, S. Ertman, P. Lesiak, A.W. Domański, A. Czapla, R. Dąbrowski, E. Nowinowski-Kruszelnicki, J. Wójcik, Opto-Electron. Rev. 14, 329 (2006).

[5] T. Nasiłowski, P. Lesiak, R. Kotyński, M.K Antkowiak, F. Berghmans, P. Mergo, J. Wójcik, H. Thienpont, Proc. SPIE 5576, 68 (2004).

[6] M.M. Tefelska, M.S. Chychłowski, T.R. Woliński, R. Dąbrowski, W. Rejmer, J. Wójcik, Acta Phys. Pol. A 118, 1259 (2010).

[7] F. Du, Y. Lu, S.-T. Wu, Appl. Phys. Lett. 85, 2181 (2004).

[8] T. Larsen, A. Bjarklev, D. Hermann, J. Broeng, Opt. Expr. 11, 2589 (2003).

[9] T. Woliński, A. Czapla, S. Ertman, M. Tefelska, A. Domański, J. Wójcik, E. Nowinowski-Kruszelnicki, R. Dabrowski, IEEE Trans. Instrum. Meas. 57, 1796 (2008).

[10] T.R. Woliński, S. Ertman, M. Tefelska, A. Czapla D. Budaszewski, A.W. Domański, R. Dąbrowski, E. Nowinowski-Kruszelnicki, J. Wójcik, Mol. Cryst. Liq. Cryst. 489, 169 (2008).

[11] L. Scolari, T.T. Alkeskjold, J.R., A. Bjarklev, Opt. Expr. 13, 7483 (2004).

[12] P.J. Collings, J. Franklin Inst. 342, 599 (2005).

[13] M. Schadt, K. Schmitt, V. Kozenkov, V. Chigrinov, Jpn. J. Appl. Phys. 31, 2155 (1992).

[14] M.S. Chychłowski, S. Ertman, M.M. Tefelska, T.R. Woliński, E. Nowinowski-Kruszelnicki, O. Yaroshchuk, Acta Phys. Pol. A 118, 1100 (2010).

[15] K. Takatoh, M. Hasegawa, M. Koden, N. Itoh, R. Hasegawa, M. Sakamoto, Alignment Technologies and Applications of Liquid Crystal Devices, Taylor \& Francis, 2005.

[16] V. Chigrinov, Photoalignment of Liquid Crystal Materials: Physics and Application, Wiley-SID series, UK 2008.

[17] V. Chigrinov, E. Prudnikova, V. Kozenkov, H. Kwok, H. Akiyama, T. Kawara, H. Takada, H. Takatsu, Liq. Cryst. 29, 1321 (2002).

[18] T.-C. Lin, S.-C. Yu, P.-S. Chen, K.-Y. Chi, H.-C. Pan C.-Y. Chao, Current Appl. Phys. 9, 610 (2009).

[19] G.P. Sinha, B. Wen, C. Rosenblatt, Appl. Phys. Lett. 79, 2543 (2001).

[20] J. Baran, Z. Raszewski, R. Dabrowski, J. Kedzierski, J. Rutkowska, Mol. Cryst. Liq. Cryst. 123, 237 (1985).

[21] R. Dąbrowski, J. Dziaduszek, T. Szczuciński, Mol. Cryst. Liq. Cryst. 124, 241 (1985).

[22] M.S. Chychłowski, T.R. Woliński, Photon. Lett. Poland 2, 77 (2010).

[23] M.S. Chychłowski, S. Ertman, T.R. Woliński, Photon Lett. Poland 2, 28 (2010). 